Copyright 1990 Society of Photo-Optical Instrumentation Engineers. One print or electronic copy may be made for personal use only. Systematic reproduction and distribution, duplication of any material in this paper for a fee or for commercial purposes, or modification of the content of the paper are prohibited.

\title{
Recovery of 3-D Motion and Structure by Temporal Fusion
}

\author{
Tarek M. Sobh and Kwangyoen Wohn
}

GRASP Laboratory

Department of Computer and Information Science

School of Engineering and Applied Science

University of Pennsylvania, Philadelphia, PA 19104

Tarek M. Sobh and Kwangyoen Wohn, "Recovery of 3-D Motion and Structure by Temporal Fusion", Proc. SPIE 1198, Sensor Fusion II: Human and Machine Strategies, 147 (March 1, 1990); doi:10.1117/12.969971; 


\title{
Recovery of 3-D Motion and Structure by Temporal Fusion
}

\author{
Tarek M. Sobh and Kwangyoen Wohn \\ GRASP Laboratory \\ Department of Computer and Information Science \\ School of Engineering and $\Lambda$ pplied Science \\ University of Pennsylvania, Philadelphia, PA 19104
}

\begin{abstract}
ABSTRAC'T
We discuss the problem of rocovering the J-D motion and structure. An algorithm for couputiug the caucra motion and the orientation of planar surface is developed. I6 solves for the 3-D motion aud strneture iteratively given two suecessive image frames. We further improve the solution by solving the ordinary differential cyua. tions which describe the evolution of motion and structure over time. The robustness of the eutire process is demonstrated by the experiment with a moving camera which "flies" over a terrail model.
\end{abstract}

\section{INTRODUCTION}

The problem of recovering scene strueture and the camera motion relative to the scene has beea one of the key problems in computer vision. Many techniques have been developed for the estimation of structure aud motion prameters ( Tsai and Iluang [2], Weng et al. [7] ctc.). A lot of cxisting algorithms depend on cvaluatiug the urotion parameters between two suceessive frames in a sequence. Ilowever, recent rescarch on structure and moLion lais been directed lowards using a large number of frames to exploit the history of parametric cvolution for a morr accurate estimation and noise reduction ( Uliman [3], Hildreth and Grzywacz [6], fu and Wohn [8] etc.)

In this paper we describe a method for recovering the 3-D motion and orientalion of a plauar surface froun au evolving image sequence. The algorithm utilizes the image flow velocities in order lo recover the 3-D paramelers. First, we develop an algorithm which iteratively improves the solution given two sucessive image frames. Thr solution space is divided into three subspaces - the transiational motion, the rotational motion ant the surfarr slope. The solution of each subspace is updated by using the current solution of the olher two subspaces. The: updating process continues until the motion paramelers converge, or until no significant improvenusut is aclicverl

Second, we further improve the solution progressively by using a large number of image frames aud the ortiuary differential equations which describe the evolution of motion and structure over time. Our algoritlum uses a wesighted average of the expected parameters and the calculated paramelers using the 2-frame iterntive algorithum as eurmu solution and continues in the same way till the end of the frame sequence. Thus it kecps track of Llue pasit history of parameteric cvolution. The system was tested on a sequence of images oblained by the molion of a camera over a planar surface.

\section{MODELING}

One can model an arbitary 3-D motion in terms of stationary-scene/moving-viewer as shown in Figure 1. Thr optical Now at the image plane can be related to the 3-D world as indicated by the followiag pair of craatiouioriginally derived by Longuel-Higgins and Prazdny [1], for each point $(x, y)$ in the image plane :

$$
\begin{aligned}
& v_{z}=\left\{x \frac{v_{z}}{z}-\frac{v_{x}}{z}\right\}+\left[x y \Omega_{x}-\left(1+x^{2}\right) \Omega_{Y}+y \Omega_{z}\right] \\
& v_{y}=\left\{y \frac{v_{z}}{z}-\frac{v_{x}}{z}\right\}+\left[\left(1+y^{2}\right) \Omega_{X}-x y \Omega_{Y}-x \Omega_{z}\right] .
\end{aligned}
$$

where $v_{z}$ and $v_{y}$ are the image velocity at image location $(x, y),\left(V_{x}, V_{Y}, V_{z}\right)$ and $\left(\Omega_{x}, \Omega_{y}, \Omega_{z}\right)$ are the trauslatioual and rotational velocity vectors of the observer, and $Z$ is the unknown distance from the cannera to the olvect. 
For planar surfaces, the $\mathrm{Z}$ function is simply $p X+q Y+Z_{0}$, where $p$ and $q$ are the planar surface orientations. The situation becomes, for each point, two equations in eight unknowns, namely, the scaled trausiationat velorities


could be used to solve those equations by differentiating the flow field and by using approximate unethodis to fund the flow field derivalives. The existing methods for compuling the derivatives of the flow field usually ito uoL. pFouluev accurate results. Our algorithm uses a discrete method instead, i.c, the vectors at it mumber of points in the plain is determined and the problem reduces to solving a system of nonlincar equations, a pair of equations represents the flow at each point as follows :

$$
\begin{aligned}
& v_{z}=(1-p x-q y)\left(x \frac{v_{z}}{z_{*}}-\frac{V_{x}}{z_{*}}\right)+\left[x y \Omega_{X}-\left(1+x^{2}\right) \Omega_{Y}+y \Omega_{z}\right] \\
& v_{y}=(1-p x-q y)\left(y \frac{\nu_{z}}{z_{*}}-\frac{y_{x}}{z_{*}}\right)+\left[\left(1+y^{2}\right) \Omega_{X}-x y \Omega_{Y}-x \Omega_{z}\right]
\end{aligned}
$$

It should be noticed that the resulting system of equations is nonlinear, however, it has some linear propertirs. The rotational part, for example, is Lotally lincar, also, for any combination of two spaces animg the rotational, transiational and slope spaces, the system becomes linear. For the system of equations to be cousisiant, we wural the flow estimates for at least four points, in which case there will be cight equations in eight unknowus.

\section{TWO-FRAME ALGORITHM}

The algorithm takes as input the estimale of the flow vectors, at a number of pouts $\geq 4$ obtained from motion between two images. It iterates updating the solution of each subspace by using the solution of the other two subspaces. Each update involves solving a linear system, thereby it requires to solve three linear systerns to complete a single iteration. This process continues until the solution converges, or until no significant. improvenent is unale. The algorithm proceeds as follows :

1. Set $p, q=0$;

input the initial estimate for rotation ;

Solve the linear system for translation;

2. Use the translation and rotation from step 1 ;

Solve the linear system for the slope;

3. Set $i=1$;

While ( $i \leq$ Max. Ilerations) and (no convergence) Do

Solve for the rotalions using latest estimales of transiations, $p$ and $q$;

Solve for the translations using latest estimates of rotations, $p$ and $q$;

Solve for $p, q$ using latest estimates of translations and rotations; end While ;

\subsection{Complexity Analysis}

As we mentioned earlier, one should notice in the equations relating the flow velocities with the slope, rotatinnal sum transiational velocities that they are "quasi-linear", if one can say 50. The equations exhibit some linear properties. This suggests that a purely iterative technique for solving non-linear equations might not be an exectlent choice, since, the variables are linearly related in some way. To think of a way of "inverting" the relations might he a good start, although to do that without a framework based on iterating and gravilating lowards a solution is unt a gronl idea.

This makes one think of applying a method which converges faster than a purely iterabive scheme lihe Nextomis method. Ilowever, the complexity of Newton's method is delermined by the complexily of computing the inverse Jacobian, which is of an order of $N^{3}$, or $N^{2.81}$ multiplications as the lower bound using Strassen's techuique. In our

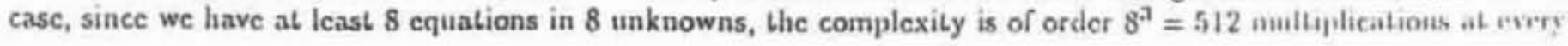


iteration, and the method does not make any use of the fact that the set of equations at haud extubuts some linear properlics.

The algorithm proposed, on the other hand, makes very good use of the fact that there are some linearity in the equations, by inverting the set of relations for each subspace at every iteration. The complexily at every iteratien is of the order of the complexity of computing the psucdo-inverse which is of the order of $\left(3^{3}+3^{3}+2^{3}\right)$ multiplicatinn at each ileration, where the first 3 comes from solving the system for the rotational variables, the seronel 3 is for the translations, the last 2 is for $p$ and $q$. This is cqual to 62 multiplications at every itcration, which is significantly less than the 512 multiplications in a method like Newton's for cxample. It was noticed that the algerithu couvergeit to solution in a very small number of iterations for most experiments we have conducted so far. The maximum number of iteralions was 7.

Using the latest solution obtained from the two-frame analysis as the initial condition for the next two-fraum: problem in the image sequence would further decrease the complexily, as the next sel of paramelers would, most probably, be elose in values to the current parameters, thus the number of iterations necded to canverge: to the new solution would decrease significantly.

\subsection{Obscrvatious}

- The algorithm is not sensitive to the initial condition of the orientation paraunicrs. 17 lir plane is sumply assumed to be a frontal one at the beginning. The slope parameters evolves with itcratious.

- The algorithm is sensitive to input noise just like other existing algorithms, some experiunents showes thw. sensitivity with respect to the change of viewing angle, table 3 includes some results of those experiments. Similarly, the algorithm performs better for a large number of points that are evenly distributed throughan the planar surface, than it docs for clustered, smaller number of image poinls.

- It is proven that there exists dual solutions for such systems. Ilowever, if our method gravitates towarils a "fixed point" in the solution space we can find the other explicitly in Lerms of the first one from the retations given by Waxman and Ullman [1].

\section{MULTI-FRAME ALGORITHM}

The ordinary differential equations that describe the evolution of motion and structure paranurters arr use, to find the expression for the expected parameter change in lerms of the previous paraneter estimales. The resperled change and the old estimates are then used to predict the current motion and structure parameters.

At time instant $t$, the planar surface equation is described by

$$
Z=p X+\eta Y+Z_{0}
$$

To compute the clange in the structure parameters during the time interval dl, we differeatiate the above cyuation to get

$$
\frac{d Z}{d t}=p \frac{d X}{d t}+X \frac{d p}{d t}+q \frac{d Y}{d t}+Y \frac{d q}{d l}+\frac{d Z_{0}}{d t}
$$

The time derivatives of $(X, Y, Z)$ in the above expression are given by the three components of the vector $-(V+\Omega \times R$.) that represent the relative motion of the object with respect to the camera. Substituting these components for the derivatives and the expression $p X+q Y+Z_{0}$ for $Z$ we can get the exact differentials for the slopes and $Z_{a}$ as

$$
\begin{gathered}
d Z_{0}=Z_{0}\left[\left(\Omega_{Y}+V_{X}\right) p-\left(\Omega_{X}-V_{Y}\right) q-V_{Z}\right] d t \\
d p=\left[p\left(\Omega_{Y p}-\Omega_{X q}\right)+\left(\Omega_{Y}+\Omega_{Z}\right)\right] d t \\
d q=\left[\eta\left(\Omega_{Y} p-\Omega_{X q}\right)-\left(\Omega_{X}+\Omega_{Z} p\right)\right] d t
\end{gathered}
$$


Using the above relations, we can compute the new structure paramelers at time $t+d t$ as

$$
\dot{p}=p+d p, \dot{q}=q+d q \text { and } \dot{Z}_{0}=Z_{0}+d Z_{0}
$$

Thus the slope parameters cvolve at lime $t+d t$ as follows :

$$
\left[\begin{array}{l}
\dot{p} \\
i
\end{array}\right]=\left[\begin{array}{l}
p \\
q
\end{array}\right]+\left[\begin{array}{ccc}
\Omega_{Y p}-\Omega_{X} q & \Omega_{z} & \Omega_{Y} \\
-\Omega_{Z} & \Omega_{Y p}-\Omega_{X} q & -\Omega_{X}
\end{array}\right]\left[\begin{array}{l}
p \\
q \\
1
\end{array}\right] d t
$$

The new translational velocity $\dot{V}$ at lime $t+d t$ can be found in the absence of accelerations from

$$
\dot{\mathrm{v}}=\mathrm{V}+\mathrm{V} \times \Omega d l
$$

Dividing $\dot{V}$ by $\dot{Z}_{0}$ we get the new expected scaled translational velocity components at tiuc $t+i l t$ as follows

$$
\left[\begin{array}{l}
\dot{V}_{X} \\
\dot{V}_{Y} \\
\dot{V}_{z}
\end{array}\right]=\left[\begin{array}{l}
V_{X} \\
V_{Y} \\
V_{Z}
\end{array}\right]+\left[\begin{array}{ccc}
-s & \Omega_{z} & \Omega_{Y} \\
-\Omega_{Z} & -s & \Omega_{X} \\
\Omega_{Y} & -\Omega_{X} & -s
\end{array}\right]\left[\begin{array}{l}
V_{X} \\
V_{Y} \\
V_{Z}
\end{array}\right] d t .
$$

where $s$ is expressed as follows :

$$
s=\left(\Omega_{Y}+V_{X}\right) p-\left(\Omega_{X}-V_{Y}\right) q-V_{Z}
$$

The expected rotational parameters at lime $t+d l$ remain equal to their values at time $l$ since

$$
\hat{\Omega}=\Omega+\Omega \times \Omega d l=\Omega
$$

and thus

$$
\left(\Omega_{x}^{*}, \Omega_{Y}^{\prime} \Omega_{z}^{\prime}\right)=\left(\Omega_{X}, \Omega_{Y}, \Omega_{z}\right)
$$

Our algorithm uses a weighted average of the expected parameters at time $t+d l$ from the above equalious aut the calculated parameters using the two-frame iterative algorithm as the solution at lime $t+d l$, and continues in the same way until the end of the frame sequence. Thus it keeps track of the past history of parameleric cvolution. The behaviour of the two-frame algorithm and the multi-frame algorithm can be conceptualized as a control sysicm as shown in figures $2 \mathrm{a}$ and $2 \mathrm{~b}$.

\section{RESULTS}

The algorithm was run on a sequence of image data. The images were those of a planar surface being apjwoaclisal by a video camern mounted on a robot arm. The plane consisted of 120 dots. The sequenec sitmiated the situation where an airplane approaches a runway for landing. One may think of the dots as lights to guide thic airplane during a night landing. The actual rolational and translational velocities between cach two subsequmat shots were $\Omega_{X}=-3^{\circ}, \Omega_{Y}=0^{\circ}, \Omega_{Z}=-5^{\circ}, V_{X}=0 \mathrm{~mm}, V_{Y}=10 \mathrm{~mm}$ and $V_{Z}=20 \mathrm{~mm}$. To delernine the flow vectors, the first order moments were used to calculate the center of mass of each one of the dols in the image sequesice aud then they were matehed across the image sequence. Thus, there were 120 points at which the $x$ and $y$ displacements wern available as the approximation to the flow velocities. In real image date, more claborated flow recovery algorillum should be used in order lo delermine the flow ficld accuralcly.

Tables $\mathrm{la}$ and $\mathrm{Ib}$ are the recovered and actual parameters when the two-frame algorithm is uscd. Table 2 includies the parameters computed from the multi-frame algorithm, using the weighting factor $=1 / 2$. Table 3 includer the results of varying the view angle for the two-frame algorithm. It should be noled that some of the paraureter improved significantly when we used the updating mechanism and kept track of the history of evolution of the motion and strueture paramelers. The translational velocities in the $y$ and $z$ directions and the plane orientation in the $y$ direction were recovered more accuralely at the end of the sequence using the second algorithm. However, error propagation caused a slight delerioration in the recovered values of a few parameters at the end of the experinusul 

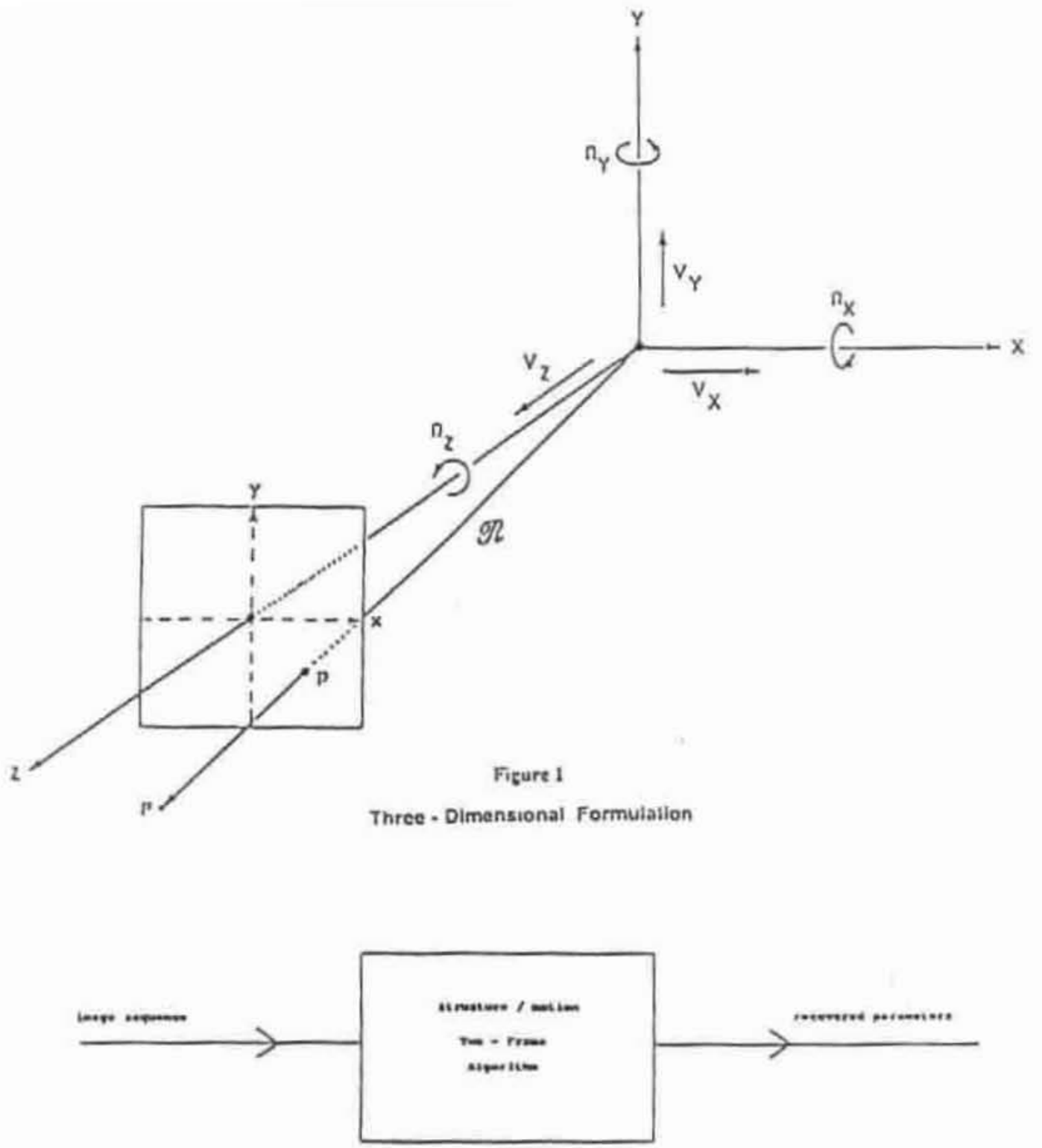

Fewre 2 s

Tre.-Prane Aigerillim

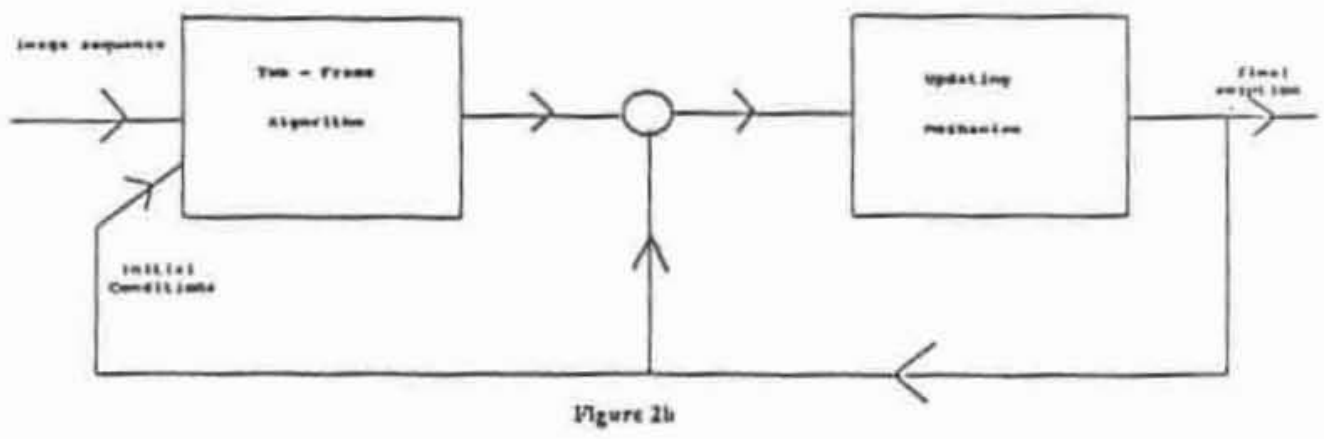

Mulit - Froune Algorlihin

Updaling Mechanism as a Controt Sysiem 

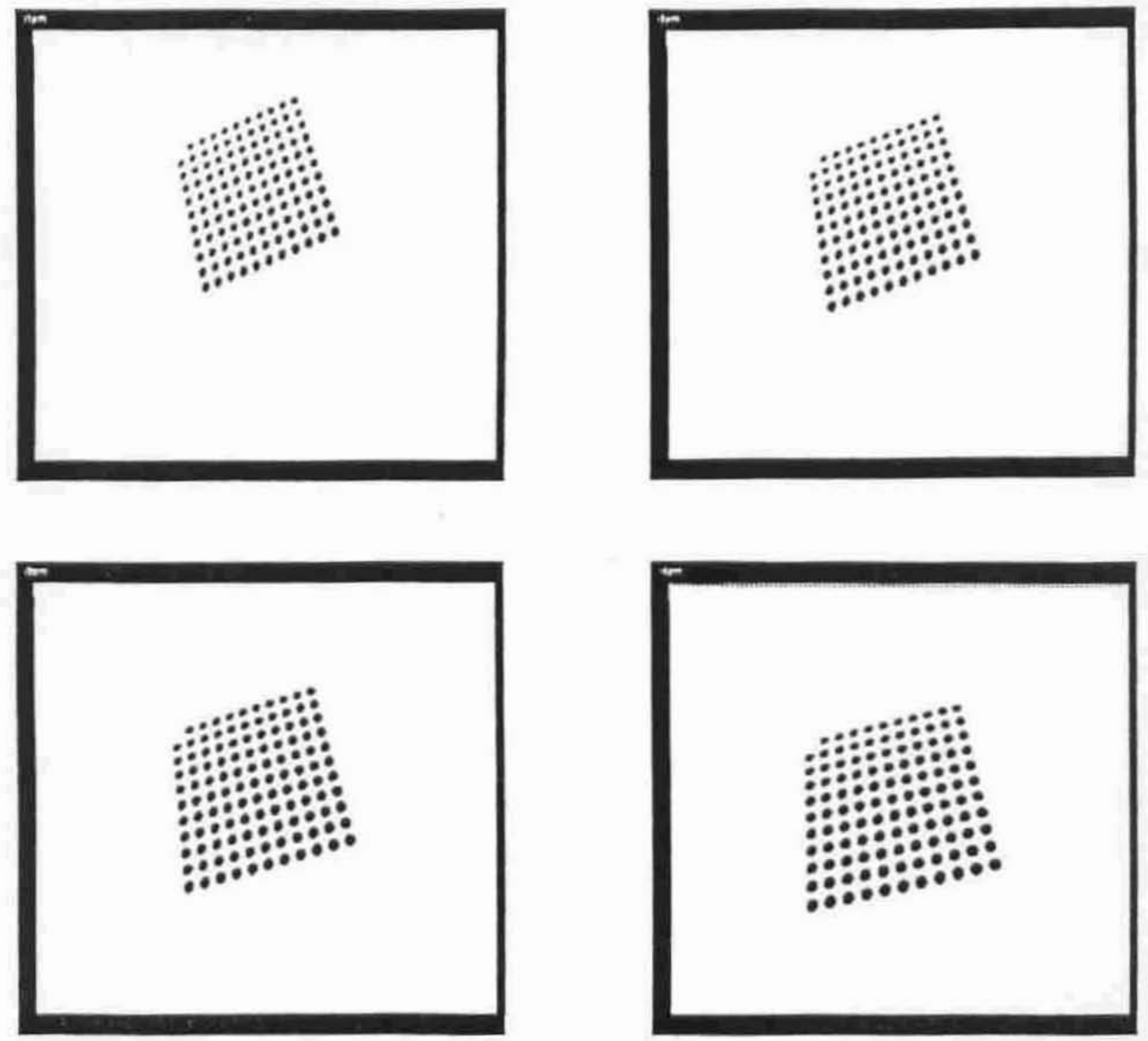

The Image sequence ( il $>$ i4 )

\begin{tabular}{||c|c|c|c|c|c|c|c|c||}
\hline \hline Parameters & II $\succ$ I2 & Actual & I2 $\succ \succ$ IS & Actual & IS $\succ$ I/ & Actual & Ih $\succ \succ$ I5 & Aclual \\
\hline \hline$\Omega_{x}$ & -0.096 & -3.0 & 0.762 & -3.0 & 0.429 & -3.0 & -0.224 & -3.0 \\
\hline$\Omega_{y}$ & -0.162 & 0.0 & -0.042 & 0.0 & 0.016 & 0.0 & 0.108 & 0.0 \\
\hline$\Omega_{z}$ & -2.537 & -5.0 & -2.889 & -5.0 & -2.82 & -5.0 & -3.005 & -5.0 \\
\hline$V_{x}$ & 1.691 & 0.0 & 1.25 & 0.0 & 1.276 & 0.0 & 1.12 & 0.0 \\
\hline$V_{y}$ & 9.25 & 10.0 & 10.71 & 10.0 & 8.22 & 10.0 & 4.8 & 10.0 \\
\hline$V_{x}$ & 15.46 & 20.0 & 15.22 & 20.0 & 17.55 & 20.0 & 18.23 & 20.0 \\
\hline$p$ & 13.14 & 17.32 & 4.7 & 16.56 & 9.76 & 14.36 & 9.05 & 12.12 \\
\hline$q$ & 30.875 & 12.25 & 22.95 & 13.34 & 29.99 & 18.56 & 33.84 & 22.73 \\
\hline \hline
\end{tabular}

Table 1a

Recovered Parameters using the 2-Frame Algorithm 



The Image sequence $\{$ i5 -> i8 $\}$

\begin{tabular}{||c|c|c|c|c|c|c||}
\hline \hline Paramelcrs & I5 $\succ \succ$ I6 & Actual & I6 $\succ$ I7 & Actual & I7 $\succ$ I8 & Actual \\
\hline \hline$\Omega_{x}$ & -0.136 & -3.0 & -2.9 & -3.0 & -3.04 & -3.0 \\
\hline$\Omega_{y}$ & 0.072 & 0.0 & -3.7 & 0.0 & 0.159 & 0.0 \\
\hline$\Omega_{z}$ & -2.297 & -5.0 & -5.32 & -5.0 & -3.802 & -5.0 \\
\hline$V_{x}$ & 0.806 & 0.0 & 2.16 & 0.0 & 0.7 & 0.0 \\
\hline$V_{y}$ & 2.963 & 10.0 & 5.54 & 10.0 & 7.167 & 10.0 \\
\hline$V_{z}$ & 18.53 & 20.0 & 11.35 & 20.0 & 16.934 & 20.0 \\
\hline$p$ & 17.94 & 13.67 & 22.04 & 10.23 & 15.07 & 4.42 \\
\hline$q$ & 13.57 & 37.38 & 25.04 & 45.51 & 71.06 & 78.36 \\
\hline \hline
\end{tabular}

Table 1b

Recovered Parameters using the 2-Frame Algorithm 


\begin{tabular}{||c|c|c|c|c|c|c|c|c||}
\hline \hline Paramelcrs & $I I-\succ$ I2 & Aclual & $I 2-\succ$ I3 & Actual & $I 3 \rightarrow \succ$ Ih & Aclual & Ih $\succ \succ$ I. & Aclual \\
\hline \hline$\Omega_{x}$ & -0.1 & -3.0 & 0.33 & -3.0 & 0.384 & -3.0 & -0.08 & -3.0 \\
\hline$\Omega_{y}$ & -0.214 & 0.0 & -0.126 & 0.0 & -0.05 & 0.0 & 0.0286 & 0.0 \\
\hline$\Omega_{z}$ & -2.64 & -5.0 & -2.67 & -5.0 & -2.8 & -5.0 & -2.09 & -5.0 \\
\hline$V_{x}$ & 1.634 & 0.0 & 1.25 & 0.0 & 1.06 & 0.0 & 0.0 & 0.0 \\
\hline$V_{y}$ & 0.933 & 10.0 & 10.42 & 10.0 & 9.614 & 10.0 & 7.49 & 10.0 \\
\hline$V_{x}$ & 14.49 & 20.0 & 14.96 & 20.0 & 16.55 & 20.0 & 17.77 & 20.0 \\
\hline$p$ & 11.01 & 17.32 & 9.64 & 16.56 & 9.68 & 14.36 & 10.02 & 12.12 \\
\hline$q$ & 26.5 & 12.25 & 21.5 & 13.34 & 26.77 & 18.56 & 30.43 & 22.73 \\
\hline \hline
\end{tabular}

\begin{tabular}{||c|c|c|c|c|c|c||}
\hline \hline Paramelcrs & $I 5-\succ I 6$ & Aclual & $I 6-\succ I \gamma$ & Actual & $I \gamma-\succ I \delta$ & Aclual \\
\hline \hline$\Omega_{x}$ & -0.11 & -3.0 & -2.75 & -3.0 & -2.89 & -3.0 \\
\hline$\Omega_{y}$ & 0.045 & 0.0 & -1.8 & 0.0 & -0.8 & 0.0 \\
\hline$\Omega_{z}$ & -2.595 & -5.0 & -3.97 & -5.0 & -3.89 & -5.0 \\
\hline$V_{x}$ & 0.697 & 0.0 & 1.124 & 0.0 & 0.78 & 0.0 \\
\hline$V_{y}$ & 5.47 & 10.0 & 6.85 & 10.0 & 8.31 & 10.0 \\
\hline$V_{x}$ & 18.68 & 20.0 & 15.5 & 20.0 & 17.76 & 20.0 \\
\hline$P$ & 14.86 & 13.67 & 25.34 & 10.23 & 16.1 & 4.42 \\
\hline$q$ & 22.34 & 37.38 & 28.04 & 45.51 & 74.86 & 78.36 \\
\hline \hline
\end{tabular}

Table 2

Recovered Parameters using the Many-Frames Algorithm

\begin{tabular}{||c|c|c|c|c|c|c|c||}
\hline \hline Paramelers & Actual & $38^{\circ}$ & $34^{\circ}$ & $29^{\circ}$ & $25^{\circ}$ & $20^{\circ}$ & $10^{\circ}$ \\
\hline \hline$\Omega_{x}$ & -3.0 & -3.01 & -2.086 & -2.787 & -2.411 & -1.023 & 2.483 \\
\hline$\Omega_{y}$ & 0.0 & 0.16 & 0.149 & 0.165 & 0.176 & 0.318 & 0.015 \\
\hline$\Omega_{z}$ & -5.0 & -3.78 & -3.729 & -3.521 & -3.176 & -1.983 & -0.157 \\
\hline$V_{x}$ & 0.0 & 0.768 & 0.722 & 0.812 & 1.242 & 2.724 & 3.476 \\
\hline$V_{y}$ & 10.0 & 7.093 & 7.023 & 6.835 & 6.251 & 4.872 & 2.489 \\
\hline$V_{x}$ & 20.0 & 16.518 & 15.325 & 14.313 & 13.826 & 14.178 & 11.415 \\
\hline$p$ & 4.42 & 15.124 & 16.113 & 16.725 & 16.037 & 19.255 & 17.8 .37 \\
\hline$q$ & 78.36 & 70.502 & 70.547 & 68.463 & 66.165 & 63.361 & 61.163 \\
\hline \hline
\end{tabular}

Tabic 3

Effect of Varying the View Angle on the Recovered Parameters \{i7 > i8 \} 


\section{DISCUSSION}

The recovery melhod described here has a variety of applications. It can be useful in vision-guided applicalions such as autonomous landing and navigation. It may be a starting point for determining global structure - untum analysis of entire polyhedra, making it suitable for robotics applications in the "moving blocks world", Praralicl implementations could be designed for such problems, thus solving for the structure - motion paranciers for sach surface scparately. In fact solving the linear system at cach iteration could also be parallelized. Lxtra processing will be needed to segment lo image into scparale planar surfaces.

We can further improve the solution by exploiting the temporal colsercuce of 3-D motion. We can develop the ordinary differential equations which describe the evolution of motion and structurc in terms of the current. motion/structurc and the measurcments (the 2-D motion vectors) in the image planc. As an initial step we can assume that the 3-D motion is piecewise uniform in time, The extended Kalman filter cau then be used to upilate the solution of the differential cquations.

\section{REFERENCES}

\section{References}

[1] H.C. Longuch-Higgins and K.Prazdny, The interpretalion of a moung Retmal /magc, Proc. Royal Society of London B, 208, 385-397.

[2] R.Y. Tsai and S.T. Huang, "Eshimating three-dimensional motion paraneters of a rigit planar pateli", It:lik: Transactions on Acoustics, Speceh and Signal Processing, ASSP-20(6), December I081.

[3] S. Ullman, Maximizing Rigidity: The incremental recovery of $3-D$ structure from rigul and rublicry molion. $\wedge 1$ Memo 721, MIT AI lab. 1983.

[1] A.M. Waxman and S. Ullman, Surface Structure and 3-D Motion From Image Flose: 1 Kincmatic Aualysis, CAR-TR-24, Center for Automation Rescarch, University of Maryland, October 1983.

[5] M. Subbarao and A.M. Waxman, On The Uniqueness of Image Flow Solutions for Planar Surfarcs $m$ Malian, CAR-TR-113, Center for Aulomalion Rescarch, University of Maryland, April 1985.

[6] N.M. Grzywaez and E.C. Uildreth, The Incremental Rigidily Scheme for Recoveriug Structure from Malian: Position us. Velocity Based Formulations, MIT A.I. Memo No. 845, Oclober 1085.

[7] J. Weng, T.S. Iluang and N. Ahuja, "3-D Motion Estimalion, Understanding aud Prodiclion from Noiky lunagr Sequences", IEEE Transactions on Pallern Analysis and Machine Iulclligence, PАMI-9(3), May IDS7.

[8] S-L. Iu and K. Wohn, "Estimation of 3-D Motion and Structure Based on a Temporally Oriented $\Lambda$ pproach witli the Method of Regression", IEEE Workshop on Visual Motion, March 1989, Irvinc, Cᄉ, 273-281. 